\title{
JÜRGEN UNTERMANN (1928-2013). IN MEMORIAM
}

\author{
MARTÍN ALMAGRO-GORBEA \\ Real Academia de la Historia
}

El pasado 7 de febrero de 2013 ha fallecido en Brauweiler, Alemania, a los 84 años de edad, el prestigioso lingüista y epigrafista alemán y admirado colega y amigo, Profesor Jürgen Untermann.

Nacido en Rheinfelden, Baden, Alemania, el 24 de octubre de 1928, recibió su formación primaria en Brauweiler (1935-1939) y la secundaria en un Gymnasium de Frankfurt am Main (1939-1947), en cuya universidad estudió de 1948 a 1950 Filología Clásica e Historia Antigua. De 1950 a 1953 pasó a ampliar estudios a la Universidad de Tübingen sobre Filología Clásica, Historia Antigua, Latín e Indoeuropeo (Indogermanistik), esto último con el Prof. Hans Krahe, uno de sus grandes maestros, bajo cuya dirección realizó su Tesis Doctoral en 1954 con una disertación sobre Der Wortschatz des Cippus Abellanus und der Tabula Bantina, trabajo que orientó sus investigaciones hacia las lenguas itálicas indoeuropeas. En la Universidad de Tübingen fue también Asistente del Seminar für Vergleichende Sprachwissenschaft de 1953 a 1958, hasta que obtuvo una beca de la Deutsche Forschungsgemeinschaft de 1958 a 1962 para su proyecto sobre un Corpus der vorromischen Inschriften der iberischen Halbinsel, investigación que marcaría en gran medida el resto de su vida científica y su indiscutible personalidad en el campo de las lenguas prerromanas de la Península Ibérica.

De forma paralela, obtuvo en 1959 en la Universidad de Tübingen, bajo la dirección del Prof. Ulrich Schmoll, otro de sus maestros, su habilitación en la especialidad de Vergleichende Sprachwissenschaft con un estudio sobre Die venetischen Personennamen, que proseguía la línea iniciada con su Tesis Doctoral. Fruto de estos trabajos fueron sus publicaciones iniciales dedicadas a las lenguas paleoitálicas, Die vorgriechischen Sprachen Siziliens (Wiesbaden, 1958) y Die venetischen Personennamen I-II (Wiesbaden, 1961). Sobre estas investigaciones de sus primeros trabajos centradas en las lenguas antiguas de la Península Itálica, en especial sículo, véneto, osco y umbro, pero también mesapio y ligur, volvió en sus últimos años con su gran autoridad y objetividad, al publicar su ejemplar Wörterbuch des Oskisch-Umbrischen (Heidelberg, 2000), que constituye una obra capital para el conocimiento de esas lenguas de la familia indoeuropea y de su cultura.

De 1962 a 1965 fue Privatdozent de la Universidad de Tübingen, hasta que en 1965 fue nombrado Catedrático de Vergleichende Sprachwissenschaft (Lingüística Comparada) de la Universidad de Colonia. En esta universidad, en la que llegó a desempeñar el cargo de Decano de la Philosophische Fakultät en el bienio

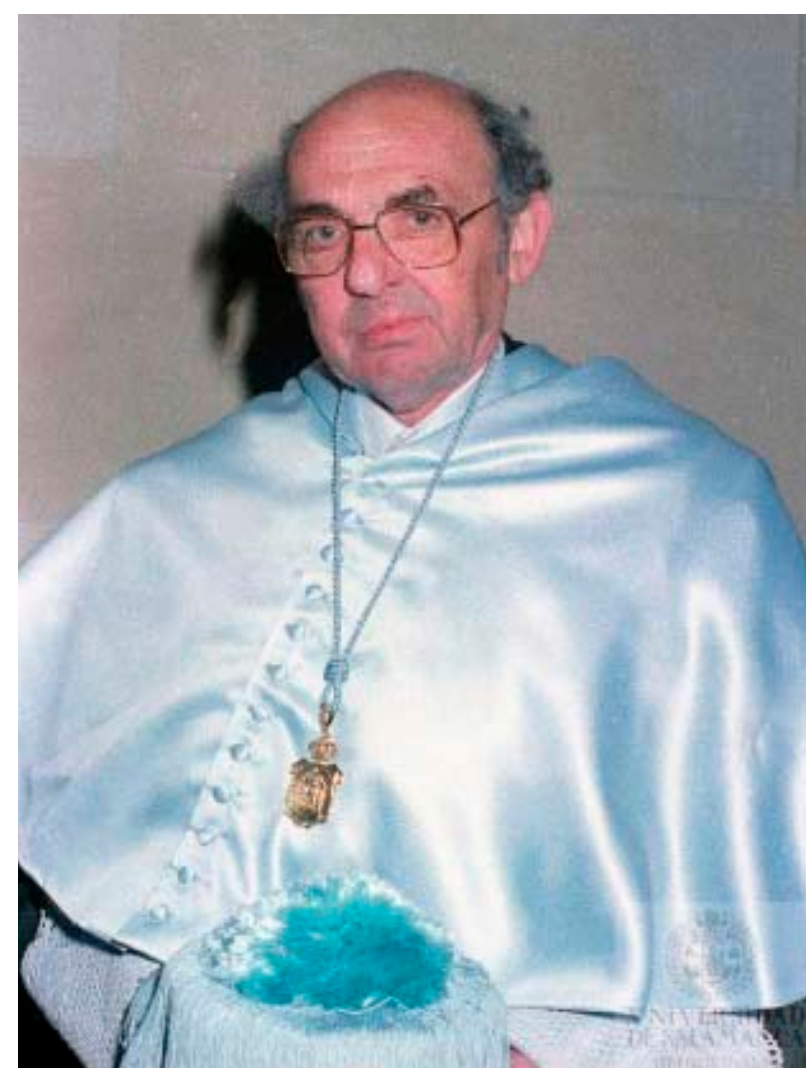

El Prof. Dr. Jürgen Untermann investido Doctor Honoris Causa por la Universidad de Salamanca en 1992. 
1971 y 1972, ejerció un largo y fecundo magisterio hasta su jubilación en 1993, en que pasó a ser Catedrático Emérito.

$\mathrm{Su}$ vocación universitaria, en la doble y complementaria faceta de investigador y de docente, se plasmó en numerosas direcciones de tesis doctorales, pero igualmente en impartir cursos, seminarios y conferencias en muy numerosas universidades: en la de Tréveris sobre Lateinische Sprachwissenschaft (1974), en la de Heidelberg sobre Lateinische und Griechische Sprachwissenschaft (1977), en Alicante (1982), Padua (1986), Nápoles (1987), Vitoria (1990), Salzburgo (1992), Guadalajara de México (1993), en la de Santiago de Compostela sobre la Hispania Indoeuropea (2004), etc., y, entre otras, por supuesto, en la Universidad de Salamanca, a la que desde 1962 se sintió inicialmente atraído por Antonio Tovar y que visitó durante toda su vida con múltiples motivos: «dos coloquios sobre lenguas y culturas paleohispánicas, el doctorado de un discípulo mío, acompañando un equipo de profesores alemanes para preparar un contrato según el programa Erasmus, varias conferencias, y por supuesto también para volver a ver mis buenos amigos entre los colegas salmantinos» ${ }^{1}$.

Como Catedrático de Lingüística Comparada de la Universidad de Colonia ha desarrollado una larga y brillante vida profesional, formando numerosos doctores que convirtieron su cátedra en centro de referencia de los estudios de «lenguas fragmentarias» (Trümmersprachen) itálicas y paleohispánicas, sobre las que versaron sus investigaciones sobre lingüística y epigrafía y sus estudios sobre onomástica y toponimia.

Aunque también dedicó algunos interesantes estudios a las lenguas griega y latina y al celta centroeuropeo, el campo de investigación preferente del Prof. Untermann, al que ha dedicado más de cincuenta años de su vida con una serie ininterrumpida de visitas al Sur de Francia, España y Portugal para conocer personalmente y estudiar todos los documentos lingüísti$\cos$, han sido las lenguas y escrituras «prerromanas»o «paleohispánicas» de la Península Ibérica, la antigua Hispania. En este campo científico es considerado internacionalmente la máxima autoridad, tanto para la lengua íbera como para las lenguas celtas o indoeuropeas, con especial interés por su toponimia y onomástica, pero también por la teonimia y el vocabulario. Untermann pronto comprendió que la principal dificultad en los estudios de las lenguas paleohispanísticas era la falta de una edición fiable de todos los textos que iban apareciendo, cada día más numerosos y que quedaban inéditos o publicados dispersos, -en ocasiones de

1. J. Untermann, VIII Centenario de la Universidad de Salamanca http://centenario.usal.es/index.php?option=com_co ntent\&view $=$ article\&id $=114 \% 3$ Ajuergen-untermann\&catid $=11 \% 3$ Atestimonios\&Itemid=123\&lang=es (2012-07-15); Investidura del Profesor Doctor Jürgen Untermann como Doctor «Honoris Causa», Universidad de Salamanca, 1992, Salamanca. forma insuficiente-, en publicaciones muchas veces locales de difícil acceso. Estos trabajos, como explícitamente reconoció al ser nombrado Doctor Honoris Causa por la Universidad de Salamanca en 1992, eran fruto del proyecto de investigación iniciado en 1956 para «poner al día los venerables, pero muy anticuados Monumenta linguae Ibericae de mi compatriota Emil Hübner ${ }^{2}$ repasando los tesoros epigráficos de museos en Madrid, Barcelona, Valencia y otras ciudades hispánicas... sobre las lenguas prerromanas de la Península Ibérica» ${ }^{3}$. Todos estos trabajos siempre los llevó a cabo en estrecha colaboración con el Prof. Antonio Tovar y con otros estudiosos, como Manuel Gómez Moreno, Julio Caro Baroja y Juan Maluquer de Motes, a los que llegó a conocer y a quienes siempre trató con toda deferencia. Este ambicioso proyecto proseguía, además, la larga tradición de estudiosos alemanes en el campo de la Lingüística de la Hispania prerromana iniciada por Wilhelm von Humboldt a inicios del siglo $\mathrm{XIX}^{4}$ y que continuó a fines del siglo XIX el epigrafista Emil Hübner ${ }^{5}$ en sus Monumenta linguae Ibericae, obra que Untermann pretendía renovar y actualizar, así como la del lingüista J. Hubschmidt ${ }^{6}$, ya en el siglo $\mathrm{XX}$.

Este inmenso trabajo ha requerido durante muchos años viajes de estudio continuos, casi innumerables, pues superan ampliamente el centenar, y largas y repetidas estancias en España para documentar las lenguas paleohispánicas y obtener un conocimiento directo de todos los epígrafes y de su contexto, objetivo que logró con tesón ejemplar y que le permitió publicar todos los documentos sobre lenguas prerromanas de la Península Ibérica, tarea en la que contó con el apoyo del Instituto Arqueológico Alemán de Madrid. En esta ingente labor, a la que dedicó los mejores años de su vida, tuvo la suerte de trabajar siempre apoyado por su inseparable compañera y colaboradora, su mujer, Bertha, que le fue de gran ayuda en todos sus estudios hasta su fallecimiento el año 2001. Este continuo contacto con nuestros museos, instituciones y estudiosos le vinculó estrechamente a España, siempre movido por el deseo de analizar personalmente y publicar

2. E. Hübner, Monumenta linguae ibericae, 1893, Berlin.

3. J. Untermann, en VIII Centenario de la Universidad de Salamanca, vid. supra, n. 1.

4. S. Rebok, M. Puig-Samper y M. Almagro-Gorbea, 2012: «Wilhem y Alexander von Humbold y la anticuaria hispana de la Ilustración», en M. Almagro-Gorbea y J. Maier (Eds.), De Pompeya al Nuevo Mundo. La Corona Española y la Arqueología en el siglo XVIII, Antiquaria Hispánica 23, 280297, Madrid.

5. Sobre E. Hübner, M. Blech, J. Maier y Th. G. Schauer (Eds.), 2013: Emil Hübner und die Altetumswissenschaft in Hispanien. Tagung zu Ehren seines 175 Geburstages (Iberia Archaeologica 14,4), Berlin.

6. Una síntesis en J. Hubschmidt, 1960: «Toponimia prerromana», en Enciclopedia Lingüística Hispánica, I, 27-66, 127149, 447-499, Madrid. 
todos los textos ibéricos, celtibéricos, lusitanos y tartesios conocidos, pues Untermann visitó todo museo y colección de España y Portugal y del Sur de Francia que contuviera material epigráfico prerromano, tarea que ha facilitado a todos los investigadores su conocimiento. Pero también trabó contacto con colegas, estudiantes y gentes muy diversas y, como señaló el Prof. J. J. Moralejo en su discurso de contestación al nombrarle Doctor Honoris Causa en la Universidad de Santiago de Compostela, de sus «estancias hispanas ha ganado Untermann un crecido número de amigos que gozamos de su trato afable y de su ciencia consumada». Todo ello le convirtió en un auténtico hispanista y en maestro de muchos investigadores españoles y portugueses que se han formado bajo su magisterio, unánimemente reconocido, hasta el punto de que se le ha considerado como auténtico fundador de los actuales estudios sobre lingüística paleohispánica.

Ya en el decenio de 1960 publicó trabajos fundamentales sobre las lenguas prerromanas de la Península Ibérica, como Sprachräume und Sprachbewegungen im vorrömischen Hispanien (Wiesbaden 1961), que tuvo el interés de traducir al Portugués (Revista de Guimarães, 77, 1962) y al Español (Archivo de Prehistoria Levantina, 10,1963). En este trabajo pasó a diferenciar dos zonas lingüísticas en la Península Ibérica, separadas por la conocida desde entonces como «línea Untermann»: una zona ibérica al Este, identificada por los topónimos en Ili-/llti-, y otra indoeuropea o céltica al Oeste, identificada por topónimos en Segy -briga, con lo que superó las obsoletas visiones del siglo XIX de W. von Humbold y E. Hübner.

Poco después, animado por el Prof. Martín Almagro, con el que también mantuvo estrecho contacto y amistad, publicaría los Elementos de un atlas antroponímico de la Hispania Antigua en la Bibliotheca Praehistorica Hispana del Instituto Español de Prehistoria del CSIC (Madrid, 1965). Su método de trabajo, basado en un uso riguroso de la cartografía histórica, hizo que antroponimia, teonimia, etnonimia y toponimia se convirtieran, a partir entonces, en ámbito preferente de sus estudios. Pero junto a estas obras de síntesis también destaca su colaboración en el estudio y edición de nuevos descubrimientos, como El tercer Bronce de Botorrita (Zaragoza, 1996), publicado en colaboración con F. Beltrán y J. de Hoz.

Sin embargo, entre todas sus numerosas publicaciones, hay que destacar la edición del impresionante corpus de inscripciones paleohispánicas, los Monumenta Linguarum Hispanicarum (MLH I-IV, Wiesbaden, 1975, 1980, 1990, 1997). Este ambicioso proyecto tenía como objetivo realizar el corpus de todos los testimonios epigráficos de lenguas prerromanas de Hispania. En cinco volúmenes, publicados a lo largo de casi 25 años, entre 1975 y 1997, recogió todas las inscripciones conocidas sobre todo tipo de soporte de todas las lenguas antiguas de Hispania, tras analizarlas, medirlas y documentarlas personalmente: las inscripciones en monedas (MLH I, 1975), las ibéricas del Sur de Francia (MLH II, 1980), las ibéricas de España (MLH III, 1990) y las inscripciones tartesias, celtíberas y lusitanas (MLH IV, 1997). Este corpus constituye una obra monumental, fruto de un trabajo constante y eficaz del Prof. Untermann a lo largo de decenios, que parece tarea imposible para una sola persona, como repetidas veces se ha reconocido. A partir de su publicación, los Monumenta han pasado a ser un instrumento fundamental para estudiar no sólo las lenguas, sino igualmente las etnias y culturas prerromanas de la antigua Hispania, por lo que resulta imprescindible para historiadores, arqueólogos, numismáticos y lingüistas. Además, esta obra ha abierto un camino ejemplar de renovación en todos esos estudios, facilitando los estudios interdisciplinares, que siempre alentó, lo que ha favorecido que decenas de investigadores en las últimas décadas hayan proseguido estos estudios siempre con la obra del Prof. Untermann como referencia, hecho que evidencia su trascendencia. Al finalizar esta opera magna, el profesor Untermann dedicó buena parte de los últimos años de su vida a una renovada atención hacia las lenguas itálicas, tras la que pasó de nuevo a ultimar el último tomo de los Monumenta ( $M L H V$ ), que esperemos que se edite próximamente.

Es imposible sintetizar en breves líneas las aportaciones tan numerosas e interesantes que los estudios lingüísticos del Prof. J. Untermann han supuesto para avanzar en el conocimiento de la Protohistoria de la Hispania prerromana al construir con datos objetivos una renovada visión etno-lingüística que resulta esencial para todos los actuales estudios de etnogénesis y sobre las sociedades del pasado interpretadas como sistema cultural. Ya hemos mencionado su clara diferenciación de dos zonas lingüísticas en la Península Ibérica con la «línea Untermann», de tanto interés como imagen sintética de la compleja etnogénesis de la Península Ibérica, puesta al día en brillantes síntesis más recientes ${ }^{7}$. Además, Untermann siempre defendió la consideración del Lusitano como una forma arcaica de las lenguas célticas, postura igualmente mantenida por el Prof. Aldo Prodocimi ${ }^{8}$, contra la opinión mayoritaria de muchos colegas españoles, postura basada en su profundidad de análisis y que se adecua mejor a la visión que ofrecen los avances paralelos en la etnogénesis de los lusitanos según la Protohistoria. Como recogió con acierto el Prof. Juan José Moralejo en la Investidura del Prof. Untermann como Doctor Honoris Causa de la Universidad de Santiago de Compostela

7. J. Untermann, 2001: Die vorrömischen Sprachen der iberischen Halbinsel. Wege and Aporien bei ihrer Entzifferung. Nordrheinisch-Westfalische Akademie der Wissenschaften. 434. Sitzung am 17.1.2001 in Düsseldorf, Wiesbaden.

8. A. Prosdocimi, 1989: «La iscrizione gallica de Larzac e la flessione dei temi in $-\mathrm{a},-\mathrm{i},-\mathrm{ja}$. Con un excursus sulla morfologia del Lusitano: acc. crougin, dat. crougeai», RömischGermanische Forschungen, 94, 190-205. 
en $2003^{9}$, el Lusitano-Galaico «mantuvo el fonema labial sordo $/ p /$, cuya eliminación se viene considerando como requisito inexcusable de celticidad...; simplemente, estamos ante un rasgo conservador o arcaizante del área galaico-lusitana, frente a la innovación que es la pérdida de $* / p /$ en otras áreas célticas», tal como también opinaba Untermann: «Ich fürchte eines Tages werden die Keltisten lernen müssen, mit dem $p$ zu leben» (vid. «Lusitanisch, Keltiberisch, Keltisch», en J. Gorrochategui, J. L. Melena y J. Santos (Eds.), 1987: Studia Palaeohispanica. Actas del IV Coloquio de Lenguas y Culturas Paleohispánicas, 74, Vitoria.), tal como también opinamos algunos protohistoriadores a partir de los rasgos étno-arqueológicos y del proceso de etnogénesis de los lusitanos, que parecen proceder de un substrato de origen celto-itálico relacionado con gentes campaniformes atlánticas del III milenio a.C. ${ }^{10}$ Igualmente, se ocupó con no menos interés del Tartesio y de su escritura, que sintetizó en el volumen IV de sus Monumenta y sus aportaciones sobre la lengua ibérica o sobre la celtibérica son aún más considerables si cabe.

Sus numerosas y rigurosas publicaciones ${ }^{11}$ lo han convertido en autoridad indiscutible sobre métodos y análisis de las lenguas paleohispánicas, en las que ha realizado profundas aportaciones en léxico, antroponimia, teonimia, etnonimia y toponimia. Sus claras visiones de síntesis resultan de profunda utilidad para avanzar en el conocimiento histórico de la compleja etnogénesis de la Península Ibérica, tema por el que se sentía a su vez atraído por ser esencial para una mejor comprensión de los fenómenos lingüísticos, lo que le hizo, junto a su carácter de investigador abierto, particularmente sensible hacia los estudios interdisciplinares, como evidencia su participación en tantos coloquios y congresos, como la Reunión Internacional sobre Paleoetnología de la Península Ibérica. Paleogénesis y Paleogeografía, celebrada en la Universidad Complutense de Madrid en $1989^{12}$.

9. J. J. Moralejo, «Acto de investidura de Jürgen Untermann como doutor «honoris causa» da USC», en http://www.usc.es/ estaticos/xornal-historico/opinion_amp14ba.html?p=9046

10. M. Almagro-Gorbea, 2009: «Lusitanos y Vettones», Lusitanos y Vettones. Los pueblos prerromanos en la actual demarcación Beira Baixa - Alto Alentejo - Cáceres-2007, 15-43, Cáceres; M. Almagro-Gorbea, 2012: recensión de la obra de «Raquel Vilaça, coord., Estelas e estatuas-menhires da Pré à Protohistória. Sabugal-2011 (Actas IV Jornadas Raianas (Sabugal, 2009), Sabugal, 2011, en Complutum, 23, 235-239.

11. Además de las obras señaladas en esta nota y en su homenaje Sprachen und Schriften..., 492-512 (vid. infra), algunas selectas publicaciones del Prof. J. Untermann pueden consultarse en http://dialnet.unirioja.es/servlet/ autor? codigo $=195017$

12. M. Almagro-Gorbea y G. Ruiz Zapatero (Eds.), 1992: Paleoetnología de la Península Ibérica, Complutum, 2-3, Madrid.
Investigador incansable, unía a su indiscutible autoritas, por todos reconocida, una gran prudencia. Pero, además, era asequible, afable y abierto con todos y siempre brindaba con toda generosidad su apoyo a cuantos solicitaran su saber, en especial a los jóvenes investigadores, muchos de ellos hoy profesores de universidad. Por ello ha ejercido un profundo magisterio sobre todas las generaciones de lingüistas hispanos posteriores, gracias a la dirección de tesis doctorales y a su participación en tribunales académicos, que han facilitado a jóvenes investigadores profundizar en estos estudios estimulados por su magisterio, además de sus aportaciones siempre brillantes en congresos, seminarios y conferencias por toda Europa. Como ha señalado con acierto el Prof. José d'Encarnação, el Prof. Jürgen Untermann «lançava hipóteses com uma humildade imensa, na perspectiva de contribuir para o avanço do conhecimento mas jamais com a pretensão de se apresentar como o "depositário único" desse conhecimento. Educava para a liberdade crítica, judiciosa e serena $\rangle^{13}$.

Una referencia particular merece la promoción de encuentros científicos, en especial los Coloquios Internacionales sobre Lenguas y Culturas Paleohispánicas, de los que fue desde sus inicios uno de los principales promotores, de cuya Comisión Internacional fue Presidente bastantes años y de los que ha sido hasta su muerte Presidente de Honor y de los que editó, junto a Francisco Villar, el volumen de Lengua y cultura en la Hispania prerromana en $1993^{14}$. Igualmente, fue editor de la Revista Beiträge zur Namenforschung y en diversas revistas científicas fue miembro del Comité Asesor, como en la revista Complutum del Departamento de Prehistoria de la Universidad Complutense, desde su fundación en 1991, lo mismo que del Consejo Científico de Palaeohispanica. Revista sobre lenguas y culturas de la Hispania antigua, editada en Zaragoza a partir del año 2001.

A pesar de su talante modesto y de que sus preocupaciones estaban dirigidas a sus estudios, su indiscutible prestigio le hizo acreedor de numerosos honores y premios a lo largo de toda su vida. Era Miembro Correspondiente (1965) y Ordinario (1979) del Deutsches Archaologisches Institut; Miembro ordinario de la Nordrhein-Westfälische Akademie der Wissenschaften de Düsseldorf (1977); Presidente de la Indogermanische Gesellschaft (1978-1982); Socio Straniero del Istituto di Studi Etruschi (1.982); Premio Javier Conde Garriga de la Asociación Numismática Española (1978); miembro de la Deutschen Forschungsgemeinschaft (1992); Membre d'Honneur de la

13. Epigraphia.hypotheses.org/194

14. Actas del $V$ Coloquio sobre lenguas y culturas prerromanas de la Península Ibérica (Colonia, 1989), publicado como J. Untermann y F. Villar (Eds.), 1993: Lengua y cultura en la Hispania prerromana, por la Universidad de Salamanca, Salamanca. 
Société Belge des Etudes Celtiques (1993); Académico Correspondiente de la Real Academia de la Historia (1994) y Correspondiente de la Reial Acadèmia de Bones Lletres, de Barcelona. Como prueba de aprecio a su gran saber y calidad docente, fue nombrado Doctor Honoris Causa por la Universidad de Salamanca en 1992 y por la Universidad de Santiago de Compostela en 2003 y también recibió el Premio Príncipe de Viana, de manos del Príncipe de Asturias, en el año 2010. Su prestigio científico internacional y su calidad humana hicieron que sus colegas y amigos le dedicaran varios homenajes al jubilarse: Sprachen und Schriften des antiken Mittelmeerraums. Festchrift für Jürgen Untermann zum 65. Geburtstag (Innsbruck, 1993) y Studia palaeohispanica et indogermanica J. Untermann ab amicis Hispanicis oblata (Barcelona, 1993).

Como corolario de una vida tan fructífera, expresamos nuestra admiración y cariño al Prof. Untermann al reconocer que la muy grata memoria de una personalidad tan admirable hará que permanezca siempre viva entre cuantos tuvimos la suerte de conocerle, pues el ejemplo de su profundo saber y su obra y su no menos profunda humanidad nos seguirán estimulando en nuestra vida y en nuestro trabajo. 